University of Nebraska - Lincoln

DigitalCommons@University of Nebraska - Lincoln

Faculty Publications from the Harold W. Manter Laboratory of Parasitology

$12-1964$

Life Cycle and Development of Prosthorhynchus formosus (Van Cleave, 1918) Travassos, 1926, an Acanthocephalan Parasite of Birds

\author{
Gerald D. Schmidt \\ University of Northern Colorado \\ O. Wilford Olsen \\ Colorado State University - Fort Collins
}

Follow this and additional works at: https://digitalcommons.unl.edu/parasitologyfacpubs

Part of the Parasitology Commons

Schmidt, Gerald D. and Olsen, O. Wilford, "Life Cycle and Development of Prosthorhynchus formosus (Van Cleave, 1918) Travassos, 1926, an Acanthocephalan Parasite of Birds" (1964). Faculty Publications from the Harold W. Manter Laboratory of Parasitology. 403.

https://digitalcommons.unl.edu/parasitologyfacpubs/403

This Article is brought to you for free and open access by the Parasitology, Harold W. Manter Laboratory of at DigitalCommons@University of Nebraska - Lincoln. It has been accepted for inclusion in Faculty Publications from the Harold W. Manter Laboratory of Parasitology by an authorized administrator of DigitalCommons@University of Nebraska - Lincoln. 


\title{
Life Cycle and Development of Prosthorhynchus formosus (Van Cleave, 1918) Travassos, 1926, an Acanthocephalan Parasite of Birds*
}

\author{
Gerald D. Schmidt and 0 . Wilford Olsen \\ Department of Zoology, Colorado State College, Greeley, and \\ Department of Zoology, Colorado State University, Fort Collins
}

\begin{abstract}
The life cycle of Prosthorhynchus formosus (Van Cleave, 1918) Travassos, 1926 is presented. The terrestrial isopods Armadillidium vulgare, Porcellio laevis, and P. scaber served as experimental intermediate hosts, and chickens and turkeys as experimental definitive hosts. After ingestion of the eggs by the isopod, the acanthor emerges from its shells within 15 min to $2 \mathrm{hr}$, enters the gut wall of its host, and remains there 15 to 25 days. It then migrates to the hemocoel and develops through the acanthella stage to the infective cystacanth by the 60th to 65th day of infection.
\end{abstract}

Van Cleave (1918) described Plagiorhynchus formosus on the basis of four specimens collected from the flicker, Colaptes auratus, at Bowie, Maryland. In 1926, Travassos reassigned this species to the genus Prosthorhynchus but gave no reasons for the change. Van Cleave (1942) disagreed strongly with this change in generic status and reaffirmed its position in Plagiorhynchus. Golvan (1956) clarified the differences between Plagiorhynchus and Prosthorhynchus and defended its position in Prosthorhynchus. This view, which was upheld by Petrochenko (1956) and Yamaguti (1963), is accepted by the present authors.

Jones (1928) extended the host list to include the chicken (Gallus domesticus), robin (Turdus migratorius), and the crow (Corvus americanus). She remarked on the possibilities of this worm becoming an important parasite of domestic fowl. Cuvillier (1934) added the catbird (Dumatella carolinensis), and a thrush

Received for publication 17 April 1964.

* Part of a thesis submitted by the senior author to the Graduate School of Colorado State University in partial fulfillment of the requirements for the Ph.D. degree, February 1964. This investigation was supported by Training Grant PHS-2E-94 (C2,3) from the National Institute of Allergy and Infectious Diseases of the $\mathrm{Na}$ tional Institutes of Health, U. S. Public Health Service, and by a fellowship from the Boettcher Foundation, Denver, Colorado.
(Hylocichla sp.), and Van Cleave (1942) the towhee (Pipilo erythrophthalmus), starling (Sturnus vulgaris), grackle (Quiscalus quiscala), and hermit thrush (Hylocichla guttata). Chandler and Rausch (1949) found it in the brown thrasher (Toxostoma rufum), and Hunter and Quay (1953) in Macgillivray's seaside sparrow (Ammospiza maritima macgillivaraii). The present report adds the red-shafted flicker (Colaptes cafer) and the domestic turkey (experimental).

Sinitsin (1929) reported finding a juvenile of Plagiorhynchus formosus in the sowbug, Armadillidium vulgare, near Washington, D. C. To date, this is the only report on the life history of $P$. formosus, although Dollfus and Dalens (1960) reported larvae of Prosthorhynchus cylindraceus in A. vulgare in France.

This work presents the complete life cycle of Prosthorhynchus formosus as observed under laboratory conditions, utilizing three species of terrestrial isopods as intermediate hosts and domestic fowl as definitive hosts.

\section{MATERIALS AND METHODS}

\section{General}

Eggs were taken from the body cavities of gravid females recovered from naturally infected robins, in which the worms were invariably located within the last inch or two of the small intestine. Nineteen of 71 robins examined were infected. The eggs were placed in centrifuge tubes, spun down, 
and refrigerated in tap water until used. Eggs stored in a refrigerator at $5 \mathrm{C}$ were still viable after 10 months.

Isopods were collected in and around Fort Collins. Armadillidium vulgare (Latreille, 1804), Porcellio scaber (Latreille, 1804), and P. laevis (Latreille, 1804) were the three species encountered, A. vulgare being by far the most common. In the laboratory, they were kept in 3-gal glass aquaria with moist sand in the bottoms and covers to prevent desiccation, at 20 to $23 \mathrm{C}$. Small pieces of wood placed on the sand provided hiding places and potatoes supplied food.

In examining 1,500 isopods collected in the general area frequented by infected robins, the only helminths found were two cystacanths of $P$. formosus in one Armadillidium vulgare. Because of this low rate of natural infection, field-caught isopods were utilized in experimentation.

Work with Tenebrio molitor, Tribolium confusum, and Melanoplus bivittatus was abandoned when it was found that eggs fed to those insects were digested within minutes.

\section{Biological studies}

Five isopods were isolated in each of several petri dishes containing a layer of moist sand, and were starved for 3 days. Small pieces of potatoes covered with eggs were then placed in each dish where they all were eaten usually during the first night. After feeding, the sowbugs were placed in a 3-gal aquarium, as described above. The larvae were recovered by dissecting the isopods in an $0.85 \% \mathrm{NaCl}$ solution.

Feeding experiments were conducted on chickens, robins, starlings, and turkeys. The birds swallowed cystacanths placed in the backs of their mouths. They were then sacrificed periodically and examined for developing worms.

Tissues of both intermediate and definitive hosts were studied to determine the extent of pathology incurred and host responses. Physiological effects of parasitism were not considered.

\section{Morphological studies}

Eggs were mounted in water for study with phase-contrast and light microscopes. Cellular details were more apparent in unhatched eggs stained with neutral red.

Acanthors were acquired from the midguts of recently fed isopods and by mixing eggs with crushed digestive glands of isopods. In both methods, mature eggs hatched within 15 to $20 \mathrm{~min}$, producing active acanthors for detailed study. Supravital staining with neutral red aided in distinguishing details of internal anatomy. Acanthors within the gut wall of the isopods were studied as whole mounts and sections. Eggs did not hatch artificially by the method of Manter (1928), as modified by Moore (1942).

Developing acanthellas removed at intervals from the body cavities of the isopods provided a series of developmental stages for study. Cystacanths, appearing as white, elongated masses within the living isopods, were removed for study. Whole mounts and serial sections were employed to elucidate the anatomy of both the acanthellas and the cystacanths.

\section{GENERAL LIFE CYCLE}

Fully embryonated eggs are voided with the feces of the host. When eaten by a suitable isopod intermediate host, they hatch in the midgut within $15 \mathrm{~min}$ to $2 \mathrm{hr}$. Hatching results from the combined effects of digestive juices of the isopod and movements of the acanthor. Within moments after ingestion, the two outer membranes of the egg spring open along preformed ridges and grooves at the poles. The acanthor then penetrates the thin, hyaline, inner membrane and escapes, increasing in size somewhat as it does so.

Active entrance of the acanthors into the gut wall usually occurred within $1 \mathrm{hr}$, but some remained in the lumen as long as $12 \mathrm{hr}$. Penetration is always completed within $24 \mathrm{hr}$ and the acanthor lies within the tissues of the gut wall.

After 15 to 25 days of apparent dormancy, the unchanged acanthor migrates to the outside of the gut where it clings loosely to the basement membrane. It then loses its spindle shape, begins to grow, and in about 2 days detaches and drops into the body cavity, transforming into the acanthella.

Progressive changes follow in which the overall size greatly increases and the organs of the mature worm are delineated. An extremely thin, transparent cyst formed around the acanthella is retained through the cystacanth stage which becomes fully developed in 30 to 40 days, but not infective until 60 to 65 days. Upon ingestion of an infected isopod by the definitive host, the proboscis of the cystacanth evaginates, pierces the cyst, and attaches to the gut wall where development to maturity occurs.

\section{DESCRIPTION OF ADULT AND EGG}

(Measurements in microns unless otherwise indicated)

\section{Adult (based on author's specimens)}

Mature female 9 to $15 \mathrm{~mm}$ long, 2 to $3 \mathrm{~mm}$ wide; mature male 8 to $13 \mathrm{~mm}$ long, 1.5 to $2.5 \mathrm{~mm}$ wide. Body elliptical to slightly ovoid, more or less flattened dorsally; trunk spines absent; color in life milky-white; hypodermal nuclei numerous, distributed evenly throughout trunk. Fully 
extended proboscis nearly cylindrical, 0.80 to 1.10 $\mathrm{mm}$ long, 25 to 29 wide in female, slightly smaller in male. Armature identical in both sexes, consisting of 15 to 18 longitudinal, regularly alternating rows of 11 to 15 hooks which measure 75 to 83 long except first and last two hooks in each row which are 55 to 65 long (measurement of longest straight line from tip of hook to top of angle between hook and root). Roots of hooks simple, occasionally irregularly knobbed or lobed, directed posteriorly, 63 to 66 long; last two or three hooks in each row with no roots. Proboscis receptacle double-walled, cylindrical, rounded at base, 1.70 to $1.90 \mathrm{~mm}$ long, 410 to 532 wide, inserted in base of proboscis at level of last three or four hooks in each row. Brain located in middle third of proboscis receptacle. Conspicuous retinacula penetrate receptacle walls laterad and insert on body wall. Lemnisci slightly longer than proboscis receptacle, claviform, flattened, containing numerous fragments of nuclei; rarely [according to Van Cleave (1942)], split along part or all of their length. Testes tandem or slightly oblique, oval, 80 to 90 long, 40 to 50 wide, about one-third body length from anterior end; anterior testis commonly somewhat smaller than posterior. Three to six tubular cement glands extend from rear margin of posterior testis to region of bursa. Genital pore dorsoterminal. Copulatory bursa lacking rays. Completely formed, living egg elliptical, averaging 75 long, 30 wide, with two shells and inner membrane; outer shell sculptured with ridges and grooves, most prominently at poles, near each of which a residual body lies between inner membrane and second shell. Acanthor within egg averages 56 by 26 .

\section{Egg}

Elliptical, mature egg (Fig. 1) with two shells and an inner membrane. Outer shell sculptured with ridges and grooves, most intensely at poles, 75 by 30 on the average. [Van Cleave (1918) originally gave the size as 48 to 60 long and 12 to 20 wide. His measurements were taken, however, on eggs while still in the body cavity of the female. This method has inaccuracies because of the optical and chemical distortion.] Inner shell highly refractive, 4 thick at poles, thinner at sides. Inner membrane elastic, hyaline, about 1 thick. A residual body between inner membrane and second shell at each pole.

\section{OBSERVATIONS ON THE DEVELOPMENT OF THE LARVA}

(Measurements in microns unless otherwise indicated)

\section{Acanthor}

Upon hatching, the spindle-shaped acanthor (Fig. 2) immediately increases in size, as reported for other acanthocephalans (Manter, 1928; Ward, 1940; Hopp, 1954). Extended larva 83 to 86 long by 36 to 38 wide.
A pair of spines 8 long with bifid bases located anteriorly and subapically, on ventral side; preceded anteriorly by one pair and followed by three pairs of smaller, simple spines. Area between the two rows of spines unadorned, serving as base of attachment for associated muscles.

Remainder of surface of larva covered with 28 to 32 regularly alternating rows of about 24 very small, backward-pointing spines. When stained with neutral red, acanthor shows outer, clear, cortical area with several nuclei and inner, more dense, medullary area (Fig. 2, C, M). Central nuclear mass measures about 12 by 12 and is located at center of medullary constriction.

After the acanthor penetrates the mesenteric intima of the isopod's mesenteron and comes to rest in enteric epithelium, it undergoes no apparent changes before migration into body cavity.

\section{Acanthella}

After clinging loosely to the outside of the basement membrane for a day or two, the rapidly growing larva drops into the body cavity of the isopod, locating in the hemocoel at the rear of the body. Size has increased to about 102 long by 57 wide. Acanthellas removed from isopods 22 days after infection (Fig. 3) measure 200 long by 95 wide. At this stage the giant nuclei of the syncytial cortical layer have enlarged and become more vesicular; each is surrounded by a clear area. The central nuclear mass has increased in size and number of nuclei; these have arranged themselves into definitive areas and are the primordia of future organ systems, as discussed below.

The primordium of the proboscis (PA) is apparent anteriorly as a syncytial mass containing six nuclei. Immediately behind the developing proboscis are many small, rapidly dividing nuclei $(\mathrm{BA})$ of the developing brain. Lateral to the brain are a number of spindleshaped cells (RA) destined to become the proboscis receptacle and inverter muscles of the praesoma. A scattered mass of nuclei (MA) behind the brain will become the gonads, ligament sacs, and musculature of the body wall. Numerous large nuclei (GA), which are the primordia of the copulatory apparatus, are located at the posterior extrem- 

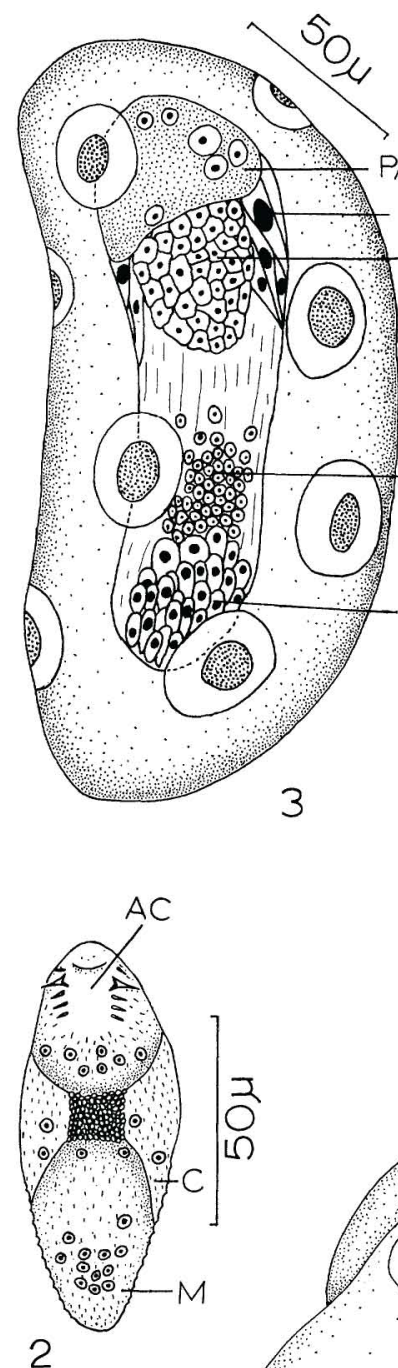
ity of the medulla. The remainder of the medulla is composed of poorly defined parenchymatous material. The cuticle becomes apparent and is loosely connected with the cortex.

Development now proceeds very rapidly. The cortex of the acanthella (Fig. 4) has become more saccular and bears a twisted stalk (S) with the spines (EH) of the acanthor's aclid organ on the tip. This stalk is buried in the soft tissue lining the hemocoel of the isopod, while the inflated portion lies in the hemocoelic cavity. The number of giant nuclei has increased to 11 , and the cortical tissue remains a very loose parenchyma.

Within the medulla, the anlagen of the body wall musculature, ligament sac, and gonads have proliferated into many cells that have migrated to the dermal area. The genital ligament (GL) has split from the body wall and moved to the center of the medulla. At this stage the sex of the worm can be determined, as the testes $(\mathrm{T})$ appear prominently within the ligament sac while the ovary is not yet discernible. Posterior to the testes is a group of nuclei (GA) that form the anlagen of the cement glands and genital apparatus.

The proboscis (Fig. 4, P) has separated laterally from the body wall but remains attached apically. The brain (BA) has continued to enlarge. The proboscis receptacle (PR) has formed as a thin-walled sac enclosing the brain and is inserted near the anterior end of the developing proboscis.

The proboscis becomes elongated, with six apical nuclei (AN) and six nuclei at the posterior end. This latter group comprises the anlagen of the proboscis retractor muscles. Extending between the two groups of nuclei are 15 to 18 longitudinal ridged structures (Figs. 4, 8, HA) that lie side by side and line the inside of the proboscis. Each ridge expands and constricts alternately. The expansions are the anlagen of the hooks, and the pattern of the adult hooks can be seen. The interior of the proboscis is filled with strands of protoplasm that become parts of the wall of the proboscis. The anterior region of the proboscis continues to elongate, and begins to evert, carrying the retractor anlagen of the proboscis along with it, causing it to migrate forward. The apical nuclei have formed distinct cells arranged in a ring around the developing proboscis.
After 26 to 28 days, the acanthella (Fig. 5) has grown and assumed a definite elliptical shape. The stalk has not increased in size, hence it appears small compared to the enlarged saccular portion which is now 1.00 to $1.50 \mathrm{~mm}$ long and 0.40 to $0.60 \mathrm{~mm}$ wide. The number of giant cortical nuclei has increased to around 20. Due to the relative increase in size of the medulla, the cortex is considerably thinner than previously.

Within the medulla, the proboscis has continued to elongate and evert. The posterior nuclear anlagen have advanced far forward and have carried strands of retractor muscle (PM) along with them. The retractor is now much advanced in development, having penetrated the posterior end of the double-walled proboscis receptacle and become inserted as two strands (RM) on the body wall. Eversion of the proboscis has resulted in the movement of many of the anlagen of the hooks to the outside layer of the proboscis (Fig. 5, HA). These can be seen as discrete, clear swellings arranged in the order characteristic for hooks of this species. The circular constriction that has developed immediately posterior to the insertion of the proboscis receptacle marks the posterior limit of the praesoma.

Five large nerve trunks extend from the brain (Fig. 7). Two (NP) are directed lateroposteriorly, one (NM) anteromedially, and two (NA) lateroanteriorly. One of the latter is considerably larger than the other and is the first to appear as a retinaculum.

The cement glands have begun to take form near the posterior end (Fig. 5, CG). Each arises from a single nucleus and is attached to a syncytial body that will later form the ducts of the cement glands. A number of large, crescent-shaped cells are arranged at the posterior extremity of the medulla. These are the anlagen of the copulatory apparatus and Saefftigen's pouch, together with their terminal ducts. These cells soon fuse into two syncytial masses (Fig. 9, GA).

By the 30th day the acanthella (Fig. 9) has elongated to dimensions of 1.60 to $1.80 \mathrm{~mm}$ long by 0.20 to $0.26 \mathrm{~mm}$ wide. The stalk may or may not be present at this stage. Cortical nuclei number about 28, with three arranged as the lemniscal ring (LR) at the posterior limit of the proboscis. The lemnisci have appeared as two small inpocketings of the 

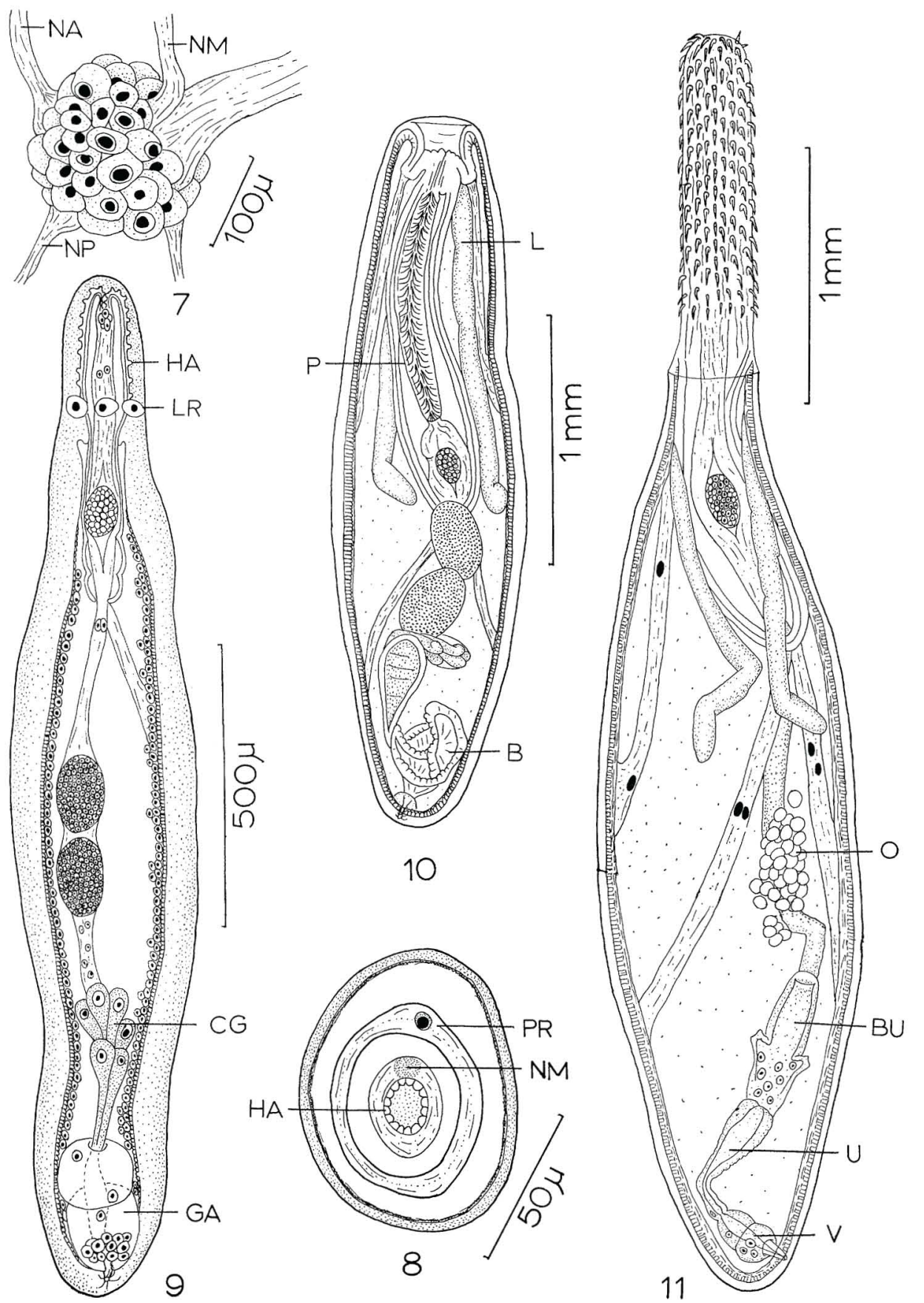

Figures 7-11. Prosthorhynchus formosus, continued. 7. Developing brain with principal nerve trunks, 28 days. NA, lateroanterior; NM, anteromedial; NP, lateroposterior. 8. Cross section at level of developing proboscis, 25 days. HA, hook anlage; NM, anteromedial nerve trunk; PR, proboscis receptacle. 9. Acanthella, 30 days. CG, cement gland; GA, anlagen of copulatory apparatus; HA, hook anlage; LR, nucleus of lemniscal ring. 10. Cystacanth, 37 days. B, bursa; L, lemniscus; P, proboscis. 11. Cystacanth, 60 days. $\mathrm{BU}$, uterine bell; $\mathrm{O}$, ovarian balls; $\mathrm{U}$, uterus; V, vagina. 
body wall directly behind the region of the lemniscal ring. They are small and difficult to see.

The proboscis has continued to evert, and the hooks (HA) have increased in size, although they are still completely imbedded in the proboscis wall. The proboscis receptacle has elongated. The circular layer of the body wall musculature has appeared and is lined internally with a layer of large round nuclei that later contribute to the formation of the longitudinal muscles. The cement glands (Fig. 9, CG) have assumed their definitive shape and number, and their ducts, together with the vasa efferentia, penetrate two large syncytial masses that are the anlagen of the copulatory apparatus (GA). The genital opening has appeared as an inpocketing of the posterior end.

By the 32nd day the proboscis has assumed the diacritical cylindrical shape of the adult but remains rather stout. The rows of hooks have completely evaginated and the proboscis now begins to reinvert at the tip. When occasional specimens failed to invert in this manner they developed into contorted and freakish shapes. Inversion is rapid, and the entire proboscis becomes invaginated within the proboscis receptacle. The tips of the hooks have elongated so as to almost reach the cuticle; a blunt, swollen projection marks the site of each. The inverted hooks pierce the cuticle in the cystacanth stage and grow in a normal manner with no damage to the surrounding tissues.

The retractor muscles of the neck are well developed at this stage and begin to withdraw the neck into the body. The longitudinal muscles of the body wall are nearly all developed and the nuclei of the anlagen have disappeared, except for two narrow lateral bands.

Great changes occur in the cortical layer. The giant nuclei become ameboid, sending slender processes radially. Finally, they fragment and sink deeper into the cortex, to lie in the inner radial layer of the hypodermis. In this same layer the lacunar system begins to form as narrow branching vacuoles that eventually anastomose to form the lacunar network. The hypodermis itself becomes fibrous with protoplasmic strands lying in all planes.
The lemnisci remain as tiny buds projecting into the body cavity. Fragmentation has also occurred in the nuclei of the lemniscal ring. Groups of these fragments remain at the site of the developing lemnisci and migrate into them as development proceeds.

The testes and associated structures have remained unchanged from the 30th day but the female organs (Fig. 6) have differentiated into a stage preliminary to that of the adult. The nuclei (OA) in the anlage of the ovary are arranged within a syncytium in the genital ligament, immediately preceding a large $\mathrm{U}$ shaped cell (UB) which is the anlage of the uterine bell. Behind this is a group of large irregular cells (UA) that constitute the anlagen of the uterus and its sphincters. The vagina (V) appears at this stage as a single large cell terminating the genital apparatus.

\section{Cystacanth}

By the 35th day of development the proboscis has completely invaginated and the cystacanth stage has begun. The early cystacanth, when dissected from the intermediate host, appears cylindrical and somewhat wrinkled and measures 2.20 to $2.40 \mathrm{~mm}$ long by 0.49 to $0.51 \mathrm{~mm}$ wide. The inverted proboscis (Fig. 10, P) nearly fills its receptacle, which is about one-half as long as the body cavity it occupies. Growth of the hooks continues; they penetrate the cuticle within 35 to 37 days and assume their definitive larval size and shape (Fig. 10). The retractor muscles of the neck have completely pulled it inward, with the result that the entire praesoma now rests inside the trunk. The anterior end of the surrounding cyst appears as an empty space, and remains so until the worm is ingested by the definitive host.

Concurrent with the final growth of the hooks, the lemnisci (Fig. 10, L) elongate and assume their adult characters. Nuclear fragments from the lemniscal ring move into them as they grow.

Following this stage of development, there is a period of slow maturation necessary for the cystacanth to become infective. The only visible changes are an overall increase in size, increased thickness and opacity of the body wall, and further inversion of the posterior end of the trunk. The infective cystacanth (Fig. 11) measures 3.0 to $4.5 \mathrm{~mm}$ in length with 
the proboscis extended, and is essentially a juvenile acanthocephalan possessing every organ of the adult worm. The ovary has formed ovarian balls (Fig. 11, O) which have escaped from the genital ligament and lie as a loosely arranged mass within the pseudocoel of the trunk region. Each ovarian ball measures about 55. When maintained at 20 to $23 \mathrm{C}$, the cystacanth becomes infective within 60 to 65 days after infection.

Six slides of developmental stages of Prosthorhynchus formosus have been deposited in the USNM Helm. Coll., No. 60023.

Photomicrographs further elucidating the development described in this paper are included in the dissertation of the same title filed with University Microfilms.

\section{DEVELOPMENT IN THE DEFINITIVE HOST}

One cystacanth, taken from the body cavity of an isopod 60 days after infection, was fed to a 2-day-old turkey poult. The bird was sacrificed 4 days later, and one juvenile female acanthocephalan was found attached to the mucosa of the small intestine. The worm measured $6.5 \mathrm{~mm}$ long and $1.2 \mathrm{~mm}$ wide, which represents a growth of approximately $2.5 \mathrm{~mm}$ in 4 days. The ovarian balls had increased in size to $87 \mu$.

Subsequent infections of young chicks and poults were accomplished, but at a low rate of infection, indicating, perhaps, a degree of natural immunity of domestic fowl to this parasite. By 3 weeks of age chickens and turkeys were completely immune to infection. The prepatent period of the parasite was not determined.

\section{PATHOLOGY AND HOST RESPONSE}

There is a marked cellular response to the invasion of the parasite in the tissues of the isopod intermediate host. At the site of penetration of the acanthor into the gut wall the intima becomes thickened and hard. There is an immediate accumulation of small, rounded blood cells with short pseudopodia; these appear to attempt to encase the parasite and overcome it. As the attack continues, the parasite changes its position, ending up some distance from the site of entry and at the margin of a zone of great hemocytic activity. Occasionally, an acanthor is overcome by the host's responses and is completely engulfed by a mass of hemocytes. It degenerates, first by decreasing in size, becoming more rounded and wrinkled, and then slowly fragmenting.

Owing to the small size of the early acanthellas within the isopod hemocoel, host reactions at this stage could not be determined. However, sections made of 25-day-old acanthellas with stalks imbedded in the surrounding soft tissues revealed much cellular response on the part of the host. Amebocytes with long, slender pseudopodia completely surround the stalk, forming a protoplasmic network. The successful parasite, however, is able to grow fast enough to prevent the restriction of the saccular portion of the body.

No gross alterations of the isopod's external organs were observed. Internally, it was noted that the ovaries of infected isopods failed to develop normally. Usually they would become vestigial, but occasionally one or both would hypertrophy and become filled with large globules of an oily substance. As this was not observed in controls, it is assumed to be an effect of parasitism by $P$. formosus. Castration of male isopods was never observed and sperm production appeared to be normal.

Histopathology of infected fowl was similar to that reported by Schmidt (1963) in the case of robins infected with this parasite.

\section{DISCUSSION}

The life cycle and developmental stages of $P$. formosus reveal a number of deviations from the patterns of development described for various Acanthocephala by other workers. The occurrence within the acanthor of an inner medullary mass separate from the cortical layer (Fig. 2, M) has not been previously described. In the present case, it can be demonstrated only through the medium of supravital staining, after which the medulla becomes easily visible. Ward (1940) illustrated what might be the medulla and referred to it as "the structure which appears to be tubular in the larva," and "lines which extend to the embryonalkern in the embryos." Hopp (1954) described a similar "clear space" around the inner nuclear mass in the acanthor of Neoechinorhynchus emydis. Both authors, however, failed to discuss the fate of this morphological feature.

So far as is known, the formation in the acanthella of P. formosus of a cuticular stalk, which serves as an organ of attachment within 
the body cavity of the host, is unique in acanthocephalan development. DeGiusti (1949) described a somewhat similar structure in the case of Leptorhynchoides thecatus. In that instance, however, the acanthor remains imbedded within the gut wall of Hyalella azteca and develops a bulging growth which protrudes into the body cavity of the amphipod. It then withdraws its attachment and assumes a teardrop shape within the hemocoel.

The area of the acanthor that bears the spines is usually called the rostellum. We believe this term misleading, for in most of the species for which the acanthor has been described the area is not definitely demarked as a protuberance, and is, in fact, usually a slight depression. Inasmuch as the term rostellum has other applications in zoology and because of the spearlike action of the spines, the term aclid organ is here proposed.

The active acanthor contracts and extends the anterior and posterior ends alternately. As the anterior end contracts, the aclid organ (Fig. 2, AC) cups inward and the spines point forward; when the anterior end extends, it snaps back into place, driving the spines into the gut tissue.

The retention of the hooks of the larval aclid organ in the acanthella stage has been recorded only by Kates (1943) for Macracanthorhynchus hirudinaceus. Their singular occurrence on the tip of the stalk of $P$. formosus gives adequate proof that the anterior end of the adult differs in orientation from the anterior end of the acanthor.

No other acanthocephalan is known to have an ovary which develops sufficiently to break into ovarian balls while still in the intermediate host. Thus, the cystacanth of P. formosus appears to be precocious, attaining an advanced stage of development within the intermediary. This may account for the rapid growth of the juvenile within the final host.

Several authors have remarked on the possibilities of $P$. formosus becoming established as a serious parasite of chickens (Jones, 1928; Cuvillier, 1934; Van Cleave, 1947; Ward, 1950). The present study suggests that chickens and turkeys have a degree of resistance to this worm and probably would not become heavily infected except in areas where numerous infected isopods occur. A simple and efficient means of preventing infection of domestic fowl would be to isolate them from isopod-infested areas for the duration of their susceptibility, which is the first 3 weeks of their lives.

\section{LITERATURE CITED}

Chandler, A. C., and R. L. Rausch. 1949. A contribution to the study of certain avian strigeids (Trematoda). J. Parasit. 34: 207210.

Cuvillier, E. 1934. New bird hosts for the acanthocephalid Plagiorhynchus formosus (Echinorhynchidae). Proc. Helm. Soc. Wash. 1: 63.

DeGiustr, D. L. 1949. The life cycle of Leptorhynchoides thecatus (Linton), an acanthocephalan of fish. J. Parasit. 35: 437-460.

Dollfus, R. P., and H. Dalens. 1960. Prosthorhynchus cylindraceus (Goeze, 1782) au stade juvénile, chez un isopode terrestre. Acanthocephala Polymorphidae. Ann. Parasit. 35: $347-349$.

Golvan, Y. J. 1956. Acanthocéphales d' oiseaux. Troisième note. Révision des espèces Européennes de la sous-famille des Plagiorhynchinae A. Meyer 1931 (Polymorphidae). Ann. Parasit. 31: 350-384.

Hopp, W. B. 1954. Studies on the morphology and life cycle of Neoechinorhynchus emydis (Leidy), an acanthocephalan parasite of the map turtle, Graptemys geographica (LeSueur). J. Parasit. 40: 284-299.

Hunter, W. S., and T. L. Quay. 1953. An ecological study of the helminth fauna of Macgillivray's seaside sparrow, Ammospiza maritima macgillivraii (Audubon). Am. Midl. Nat. 50: 407-413.

JoNes, M. 1928. An acanthocephalid, Plagiorhynchus formosus, from the chicken and the robin. J. Agr. Res. 36: 773-775.

Kates, K. C. 1943. Development of the swine thorn-headed worm, Macracanthorhynchus hirudinaceus, in its intermediate host. Am. J. Vet. Res. 4: 173-181.

Manter, H. W. 1928. Notes on the eggs and larvae of the thorny-headed worm of hogs. Tr. Am. Micr. Soc. 47: 342-347.

Moore, D. V. 1942. An improved technique for the study of the acanthor stage in certain acanthocephalan life histories. J. Parasit. 28: 495.

Petrochenko, V. I. 1956. Acanthocephala of domestic and wild animals. Vol. I. Moscow, 435 p. (In Russian.)

ScHmid, G. D. 1963. Histopathology of a robin infected with the acanthocephalan parasite Prosthorhynchus formosus. J. Colo.-Wyo. Acad. Sci. 5: 54.

Sinitsin, D. 1929. Note on an intermediate host for Plagiorhynchus formosus. J. Parasit. 15: 287.

Travassos, L. 1926. Contribuições paro o conhecimento da fauna helminthologica brasileira. 
XX. Revisão dos acanthocephalos brasileiros. Parte II, Familia Echinorhynchidae Hamann, 1892, sub-fam. Centrorhynchinae Travassos, 1919. Mem. Inst. Osw. Cruz 19: 31-125.

Van Cleave, H. J. 1918. The Acanthocephala of North American birds. Tr. Am. Micr. Soc. 37: $19-47$.

- 1942. A reconsideration of Plagiorhynchus formosus and observations on Acanthocephala with atypical lemnisci. Tr. Am. Micr. Soc. 61: 206-210.

. 1947. Thorny-headed worms (Acantho- cephala) as potential parasites of poultry. Proc. Helm. Soc. Wash. 14: 55-58.

WARD, H. L. 1940. Studies on the life history of Neoechinorhynchus cylindratus (Van Cleave, 1913) (Acanthocephala). Tr. Am. Micr. Soc. 59: $327-347$.

- 1950. Acanthocephala as possible parasites of Tennessee chickens. J. Tenn. Acad. Sci. 25: 242-243.

Yamaguti, S. 1963. Systema Helminthum. Vol. V. Acanthocephala. Interscience Publishers, New York, 423 p. 